\title{
TITLE:
}

\section{Influence of urban spatial configuration and sea breeze on land surface temperature on summer clear-sky days}

\section{$\operatorname{AUTHOR}(S)$ :}

Yamamoto, Yuhei; Ishikawa, Hirohiko

\section{CITATION:}

Yamamoto, Yuhei ...[et al]. Influence of urban spatial configuration and sea breeze on land surface temperature on summer clear-sky days. Urban Climate 2020, 31: 100578.

\section{ISSUE DATE:}

2020-03

URL:

http://hdl.handle.net/2433/246187

\section{RIGHT:}

(c) 2020 This manuscript version is made available under the CC-BY-NC-ND 40 license

http://creativecommons.org/licenses/by-nc-nd/4.0/; The full-text file will be made open to the public on 1 March 2022 in accordance with publisher's 'Terms and Conditions for Self-Archiving'.; This is not the published version. Please cite only the published version.; この論文は出版社版でありません。引用の際には出版社版をご確認ご利用ください。 


\section{Influence of urban spatial configuration and sea breeze on land surface temperature on}

2 summer clear-sky days

4 Yuhei Yamamoto 1

5 Affiliation: ${ }^{1}$ Disaster Prevention Research Institute, Kyoto University, Uji, Kyoto 611-0011 Japan.

$6 \quad$ E-mail: yamamoto_y@storm.dpri.kyoto-u.ac.jp

\section{$7 \quad$ Hirohiko Ishikawa ${ }^{1}$}

8 Affiliation: ${ }^{1}$ Disaster Prevention Research Institute, Kyoto University, Uji, Kyoto 611-0011 Japan.

$9 \quad$ E-mail: ishikawa@storm.dpri.kyoto-u.ac.jp

\section{Corresponding author: Yuhei Yamamoto}

12 *Present address: Center for Environmental Remote Sensing, Chiba University, 1-33 Yayoi-cho, Inage-ku, Chiba13 shi, Japan.

Abstract

Understanding the spatiotemporal characteristics of land surface temperature (LST), a physical quantity that greatly contributes to the formation of urban thermal environment, is essential for constructing a sustainable urban environment. This study explores the relationship between urban space, atmospheric conditions, and diurnal change characteristics of LST on summer clear-sky days in an urban area of Osaka Plain using a 10 min LST dataset retrieved from the Japanese geostationary satellite (Himawari-8) data. The principal temporal change patterns forming the diurnal cycle of LST were extracted through a principal component analysis, and their spatial variabilities were investigated through the exploitation of ground-based meteorological observation and land-use data. The result showed two temporal change patterns, identified as the amplitude and phase of the diurnal change, being extracted in different clear-sky days. A hierarchical cluster analysis confirmed that the spatial variations of such patterns corresponded to the sea breeze and urban land-use. Moreover, LST change at daytime was found to be larger in the high-density areas rather than in the low-density areas of low buildings, thereby suggesting the influence of building density on LST at daytime. 
Keywords: Himawari-8; urban heat island; land surface temperature; urban land use; sea breeze

\section{1. Introduction}

Urban heat island which is characterized by deterioration of a hot environment on an urban scale, has recently become an increasingly serious phenomenon, in addition to the rise in temperature due to global warming (e.g., Kusaka et al., 2012). The foreseeable impact of urban heat islands is exemplified by the case of the Japanese metropolitan areas, where approximately 50,000 heat-stroke patients are being sent to hospitals via ambulance yearly, with a particularly high number of 90,000 during the summer of 2018 (Japan Fire and Disaster Management Agency, 2018). In addition to this direct effect, the drop in pressure accompanying the temperature rise may cause enhanced precipitation (Seino et al., 2018) and retention of air pollutants, such as NOx and SOx, in the environment (Saitoh et al., 1996).

Thermal indices have been proposed for evaluating the thermal environment in an urban area, with such examples as wet-bulb globe temperature and universal thermal climate index, that consider various meteorological elements i.e., surface air temperature (SAT), radiant heat, humidity, and wind speed (Budd, 2008; Jendritzky et al., 2012). SAT and land surface temperature (LST) are likewise effective in evaluating the intensity of urban heat island and in obtaining a detailed spatiotemporal characteristic of the thermal environment (Memon et al., 2009). SAT and LST exhibit different spatiotemporal dynamics because the involved processes are dissimilar. SAT is generally observed in ground weather stations. In urban areas with available dense observation networks, the spatial variability characteristics of diurnal and seasonal changes of SAT have been investigated through a multivariate analysis (Kim and Beik, 2005; Suzuki and Iizuka, 2009; Oku and Masumoto, 2014).

On the other hand, LST is retrieved by polar-orbiting satellite/aircraft sensors owing to their high spatial resolution (Memon et al., 2009; Weng, 2009). The obtained LST data have been used to investigate their relationships with urban vegetation and land use. Vegetation-wise, the focus is on changes in the LST from the increase/decrease of green space (Li et al., 2009; Tsunematsu et al., 2016; Honjo et al., 2017), along with the vegetation phenology (Li et al., 2011; Xu et al., 2013). Vegetation status is represented by vegetation coverage based on land use and land cover

54 (LULC) or remotely sensed vegetation indices, such as the normalized difference vegetation index (NDVI) and vegetation indices (Weng, 2009). 
Land-use-wise, the focus is on correlations between LST and landscape metrics quantifying the horizontal urban structures (Li et al., 2011; Connors et al., 2013). The metrics measure density, shape complexity, diversity, and adjacency, among others, in LULC types. Additionally, relationships between LST and vertical urban structures were also assessed using land-use data which have building height information (Li et al., 2011; Tsunematsu et al., 2016). These studies revealed that both the cover composition and spatial configuration of the urban land surface affect the LST. Yamamoto and Ishikawa (2018a) reported that the LST in coastal cities may be affected by the sea/land breeze (i.e., a local meteorological field with diurnal cycle); thus, they stressed the inclusion of local meteorological effects when studying the influence of urban spatial configuration on LST. In the evaluation of thermal environment using instantaneous LST values obtained by polar-orbiting satellite/aircraft observations, the influences of the local meteorological field on LST may pose a challenge.

This study presents LST observations in an urban area, through Himawari-8, a Japanese third-generation geostationary satellite that can retrieve LST with high spatial (approximately $2 \mathrm{~km}$ ) and temporal (10 min) resolutions. Yamamoto and Ishikawa (2018a) attempted to apply the Himawari-8 LST product to an urban area and confirmed that its spatial and temporal resolutions are effective in obtaining the thermal characteristics of land use and local meteorological field in that area. Such advantage, especially temporal resolution, was utilized by this research to understand the influence of urban spatial configuration and sea breeze on the temporal changes of LST during the summer clear-sky days in an urban area within Osaka Plain, Japan.

\section{Data and method}

\subsection{Analyzed area and data}

Fig. 1 shows the urban study area of Osaka Prefecture, which is known to have the respective lowest and highest ratios of forest and habitable areas (the latter is calculated by subtracting the area of forests, grasslands, and bodies of water from the total area of the prefecture) in Japan prefectures (Japan Statistics Bureau, 2019). Additionally, the prefecture has the largest number of heat-stroke patients sent to hospitals via ambulance in recent years (Japan Fire and Disaster Management Agency, 2018). From the land use map in Fig. 1, there is a bay (Osaka Bay) on the west side of the analyzed area. The central urban area is occupied by high buildings, and the surrounding areas are occupied by low buildings (high or low density). 


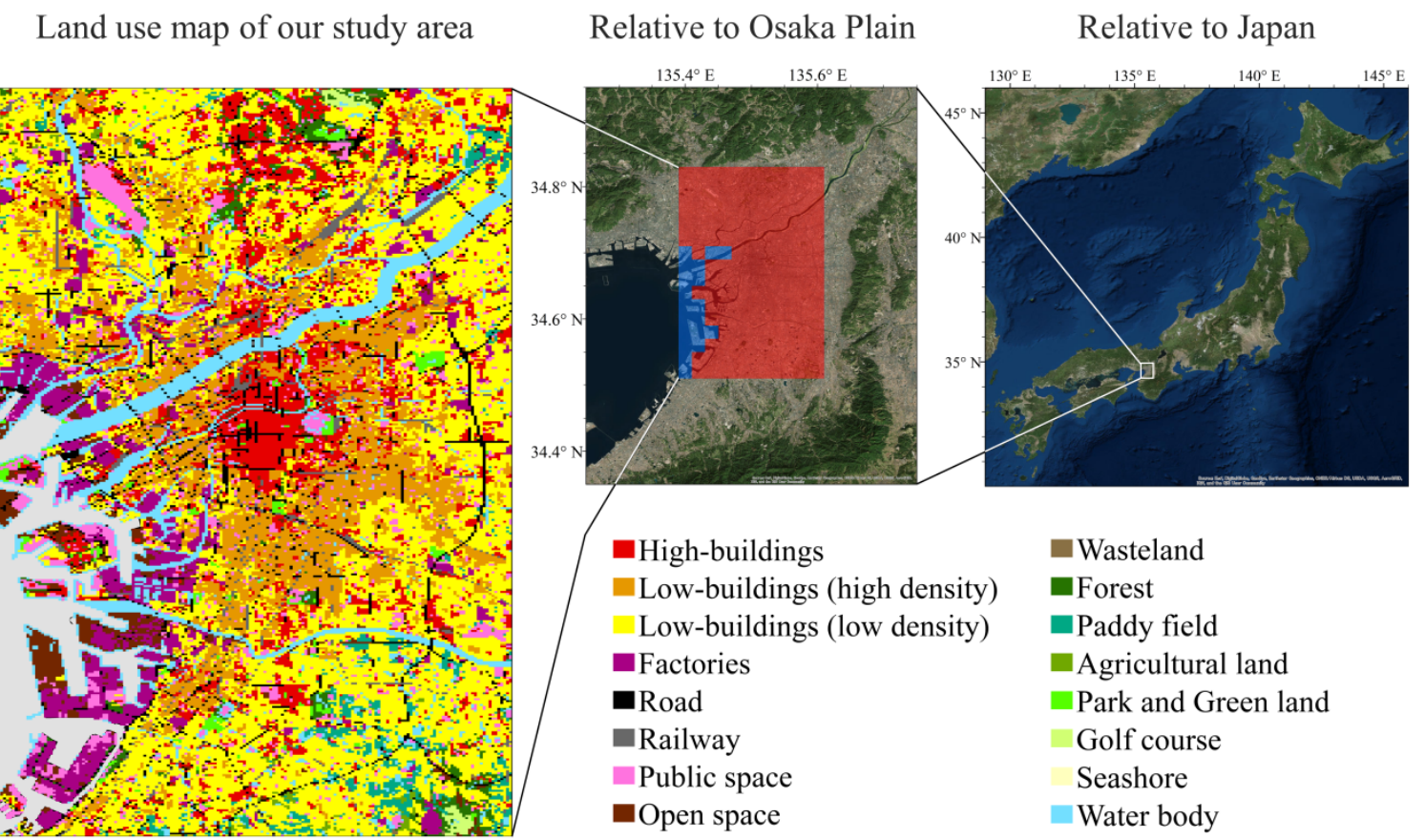

Fig. 1. Location map and land use of the study area $\left(34.51^{\circ} \mathrm{N}-34.83^{\circ} \mathrm{N}, 135.39^{\circ} \mathrm{E}-135.61^{\circ} \mathrm{E}\right)$. In the middle figure, LST pixels used in the analysis are shown in red, whereas pixels with a percentage of water surface above $50 \%$ are shown in blue.

temperatures and land surface emissivities of bands 13, 14, and 15 (centered at 10.4, 11.2 and $12.4 \mu \mathrm{m}$, respectively) of Himawari-8 in the thermal infrared region. The brightness temperature data of Himawari- 8 were provided by the Center for Environmental Remote Sensing, Chiba University, whereas the land surface emissivities were estimated by a semi-empirical method based on the land cover information and NDVI (Yamamoto and Ishikawa, 2018b). LST retrieval was limited to a clear-sky condition where the upward thermal infrared radiance from the land surface can be observed by the Himawari- 8 sensor. The spatial and temporal resolutions of the retrieved LST data were $0.02^{\circ}$ and $10 \mathrm{~min}$, respectively. A total of 157 terrestrial pixels which have water surface percentage of less than $50 \%$ were used in all pixels of the study area (Fig. 1). The satellite zenith angle in the study area ranges from $40.47^{\circ}-40.86^{\circ}$. Therefore, all pixels used in the analysis were observed at approximately the same angle. The days when the diurnal change of LST of the 157 pixels was retrieved (i.e., days with zero cloud cover) were chosen for focal analysis on the temporal change characteristics of LST. The target season was summer. The presence of clouds was judged by a cloud detection method employing Himawari-8's visible and infrared data (Yamamoto et al., 2018). The selection period was the summer season, from July 2015 of the onset of the Himawari-8 operation to August 2018. The final selected dates were August 12, 2016, July 19, 2018, and August 4, 2018. 
99 The urban area land-use segmentation mesh data of national land numerical information provided by the Ministry 100 of Land, Infrastructure and Transport of Japan (http://nlftp.mlit.go.jp/ksj/gml/datalist/KsjTmplt-L03-b-u.html; see

101 Fig. 1) were used for investigating the relationship between LST and urban land use. The spatial resolution was 100 102 m; i.e., it was resolved with approximately 400 grid of land-use information per pixel of the LST data. Furthermore, 103 the SAT, wind direction, and wind speed data from the Automated Meteorological Data Acquisition System 104 (AMeDAS) operated by the Japan Meteorological Agency, were exploited for investigating the relationship between 105 LST and meteorological field. The observation points included Osaka, Toyonaka, Sakai, and Yao (see Figs. S1-S3) 106 at 10 min temporal resolution.

\section{$107 \quad 2.2$ Method of analysis}

108 The influence of urban spatial configuration and sea breeze on the temporal changes of LST, not the instantaneous 109 LST, was the highlight of this study. Such temporal changes were defined through a summary of the original diurnal 110 changes of LST using the principal component analysis (PCA). In other words, they were the principal temporal 111 change characteristics forming the diurnal changes of LST.

The temporal resolution of the LST data was 10 min, leading to a total of 144 LSTs retrieved for each pixel 113 throughout the day. As the PCA was applied, the diurnal changes of LST were converted into the diurnal changes of 114 the deviation by subtracting the daily mean LST of each pixel. The diurnal changes of the deviation of all pixels were 115 expressed as the following $157 \times 144$ matrix $\boldsymbol{d T}$ :

$$
\boldsymbol{d} \boldsymbol{T}=\left(\begin{array}{ccc}
d T_{1,1} & \ldots & d T_{1,144} \\
\vdots & \cdots & \vdots \\
d T_{157,1} & & d T_{157,144}
\end{array}\right)
$$

116 and the $144 \times 144$ variance-covariance matrix $\boldsymbol{V}$ of $\boldsymbol{d T}$ was calculated as follows:

$$
\boldsymbol{V}=\left(\begin{array}{ccc}
s_{1,1} & \cdots & s_{1,144} \\
\vdots & & \vdots \\
s_{144,1} & \cdots & s_{144,144}
\end{array}\right)
$$

117 where the variances and covariances contained in $\boldsymbol{V}$ were given by:

$$
s_{i j}=s_{j i}=\frac{1}{157} \sum_{k=1}^{157}\left(d T_{i k}-\overline{d T_{i}}\right)\left(d T_{j k}-\overline{d T_{j}}\right)
$$

118 where $\overline{d T_{i}}\left(\overline{d T_{j}}\right)$ is a column average of elements at time $i(j)$ in $\boldsymbol{d} \boldsymbol{T}$. By solving the eigenvalue problem for $\boldsymbol{V}$, 119 the eigenvalues $\left(\lambda_{1}, \ldots, k, \ldots, \lambda_{144}\right)$ and the corresponding eigenvectors $\boldsymbol{a}_{\boldsymbol{k}}=\left(a_{k 1}, \ldots, a_{k 144}\right)$ were obtained. 
Table 1. Eigenvalues and contribution ratios from PC1 to PC5 derived by the PCA on the three analysis days.

\begin{tabular}{|c|c|c|c|c|c|c|}
\hline \multirow{2}{*}{$\begin{array}{c}\text { Principal } \\
\text { Component }\end{array}$} & \multicolumn{2}{|c|}{ August 12, 2016} & \multicolumn{2}{|c|}{ July 19, 2018} & \multicolumn{2}{|c|}{ August 4, 2018} \\
\hline & Eigenvalue & $\begin{array}{c}\text { Contribution } \\
\text { Ratio (\%) }\end{array}$ & Eigenvalue & $\begin{array}{c}\text { Contribution } \\
\text { Ratio (\%) }\end{array}$ & Eigenvalue & $\begin{array}{c}\text { Contribution } \\
\text { Ratio (\%) }\end{array}$ \\
\hline PC1 & 108.15 & 85.26 & 142.08 & 78.08 & 129.85 & 84.95 \\
\hline $\mathrm{PC} 2$ & 8.76 & 6.91 & 21.84 & 12.00 & 10.60 & 6.93 \\
\hline $\mathrm{PC} 3$ & 4.97 & 3.92 & 6.17 & 3.39 & 4.95 & 3.24 \\
\hline PC4 & 1.77 & 1.39 & 4.73 & 2.60 & 2.40 & 1.57 \\
\hline PC5 & 0.84 & 0.66 & 2.34 & 1.29 & 1.30 & 0.85 \\
\hline
\end{tabular}

120 Therefore, the number of principal components (PCs) is 144 . The $1 \times 157 \mathrm{PC}$ score of each PC was calculated as the 121 scalar product of $\boldsymbol{d} \boldsymbol{T}$ and $\boldsymbol{a}_{\boldsymbol{k}} .157$ PC scores were normalized for each PC. In this analysis, the PC score represents 122 the reflection degree of the temporal change characteristic represented by each PC in each pixel. The eigenvector 123 represents the weight corresponding to the LST deviation at each time in the calculation of the PC score.

August 12, 2016

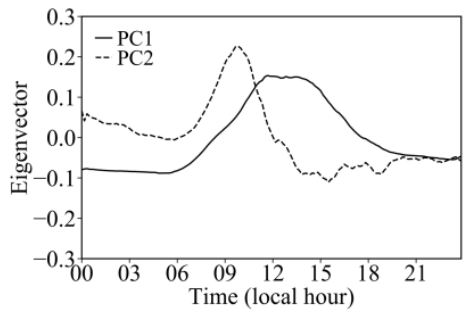

(a)

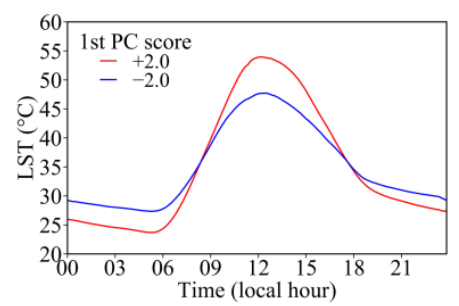

(d)

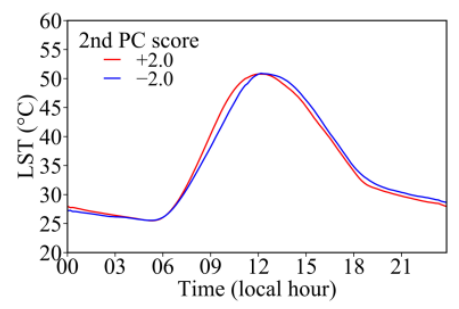

(g)
July 19, 2018

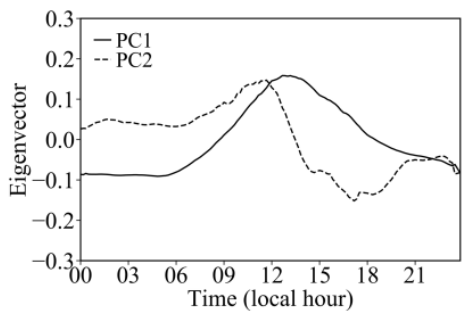

(b)

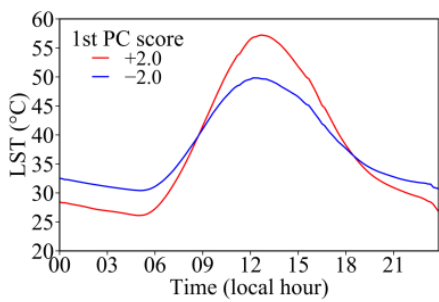

(e)

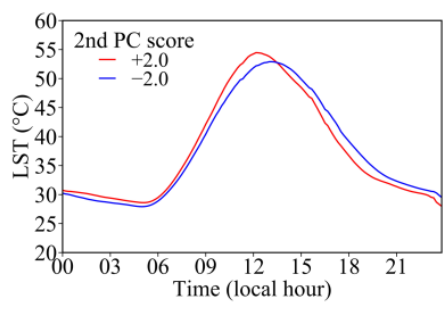

(h)
August 4, 2018

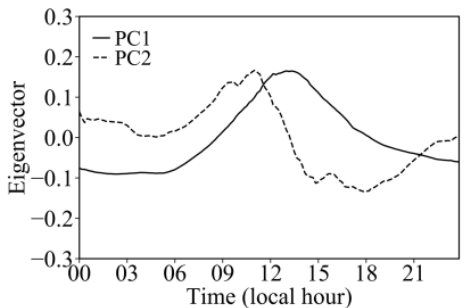

(c)

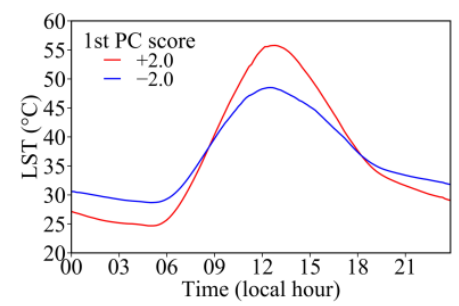

(f)

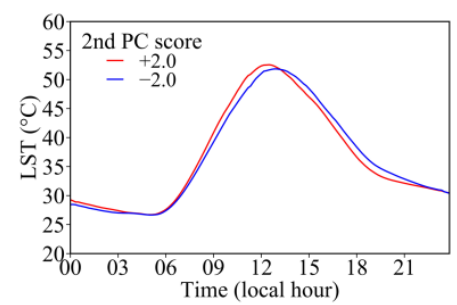

(i)

Fig. 2. (a)-(c) PC1 and PC2 eigenvectors $\mathrm{f}$ for the three analysis days. (d)-(f) Effect of PC1 on diurnal change of the average LST of the study area. (g)-(i) Effect of PC2 on diurnal change of the average LST of the study area. 


\section{PCA results}

Table 1 shows the eigenvalues and contribution ratios from the first PC (PC1) to the fifth PC (PC5) derived by the PCA. The contribution ratios of PC1 were dominant, and the cumulative contribution ratios of PC1 and PC2 were more than $90 \%$ on all 3 days. In other words, the diurnal cycle of LST in a summer clear-sky day could be adequately described by the temporal change characteristics represented by PC1 and PC2. This led to the investigation of the influence of the urban spatial configuration and meteorological field on the temporal change characteristics of LST represented by $\mathrm{PC} 1$ and $\mathrm{PC} 2$.

Figs. 2(a) to 2(c) show the eigenvectors of PC1 and PC2. The former had negative and positive components at nighttime and daytime, respectively, on all 3 days, with the positive maximum value reached around noon. Note that the temporal change characteristic represented by PC1 was emphasized around noon. Figs. 2(d) to 2(f) show the responses of diurnal change of the average LST of 157 pixels in the study area when only the normalized PC score of PC1 was changed by \pm 2.0 . For the average LST deviation of the study area, the PC scores from PC1 to PC144 were 0 . Thus, by changing only the PC1 score, the temporal change characteristics represented by PC1 can be emphasized. From Figs. 2(d) to 2(f), the amplitudes of the diurnal cycle were observed to vary with the variation of the PC score on all 3 days, implying that PC1 represents the amplitude of the diurnal cycle on the clear-sky days.

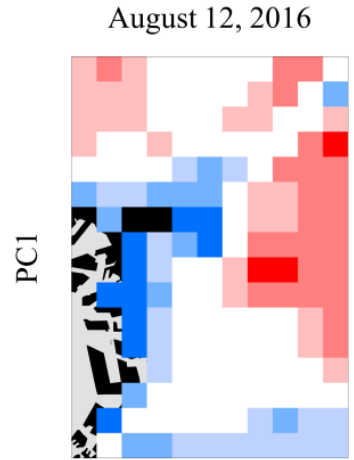

(a)

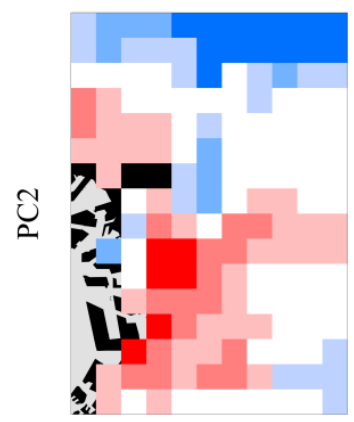

(d)

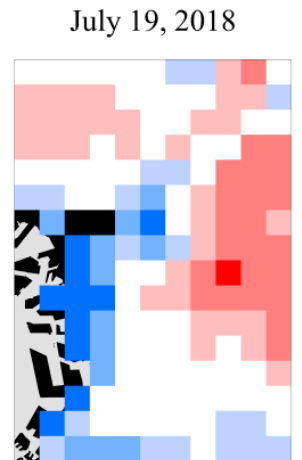

(b)

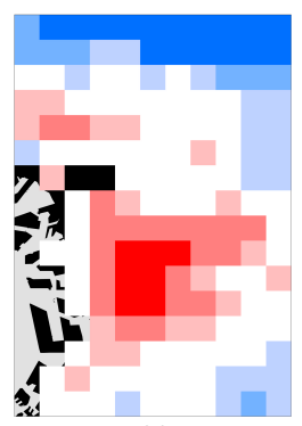

(e)
August 4, 2018

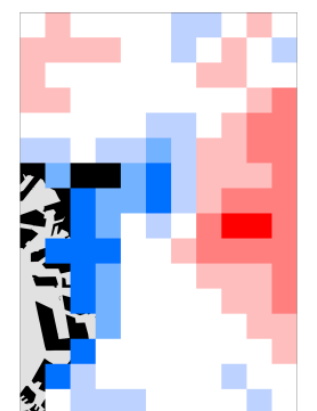

(c)

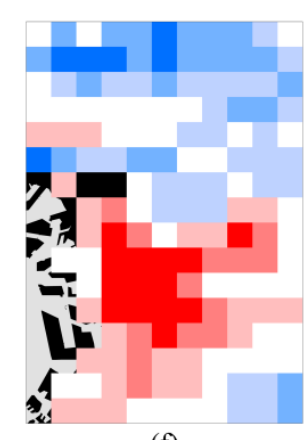

(f)

Fig. 3. Spatial distributions of the normalized PC scores of PC1 $(a-c)$ and PC2 $(d-f)$ derived by the PCA on the three analysis days. 
As shown in Figs. 2(a) to 2(c), the components of PC2 eigenvectors tended to be positive in the forenoon (i.e., the time between midnight and around noon) and negative in the afternoon (i.e., the time between around noon and midnight). The vector components took a positive maximum value from 9:00 to 12:00 when the temperature rise

144 became large, whereas they took a negative maximum value from 15:00 to 18:00 when the temperature drop was 145 large. Moreover, the components were close to 0 around noon when the vector components of PC1 took an extreme value. Figs. 2(g) to 2(i) display a visualization of the temporal change characteristic represented by PC2, similar to 147 Figs. 2(d) to 2(f). These figures imply that PC2 represents the phase shifting by the waveform leaning 148 forward/backward and independent of the amplitude.

149 As described above, a large (small) PC1 score indicates that the amplitude of the diurnal cycle is relatively large 150 (small). A large (small) PC2 score indicates that the phase of the diurnal cycle is relatively advanced (delayed). Fig. 1513 shows the spatial distributions of the scores of PC1 and PC2, with the former at a positive tendency in the inland area and at a negative tendency in the coastal area. On the other hand, the spatial variability of the PC2 score tended to be geographically opposite to that of PC1. Nevertheless, both score distributions were not diametrically opposite and seemingly corresponding to land-use distribution. For example, the scores of both PCs were low in a pixel occupied by high buildings (see Fig. 1), regardless of the area being coastal or inland.

\section{Discussion}

Fig. 4 shows the scatter diagrams of PC1 and PC2 scores for the three analysis days, with the addition of dominant land-use type and coastal distance information. Moreover, in order to objectively classify the characteristics of the distributions in Fig. 4, we performed cluster analysis (Ward's method) using the 1st and 2nd PC scores, coastal distance (pixels) and proportions of high-buildings, low-buildings (high density), low-buildings (low density), factories, vegetation, and water body of each pixel as input variables. These variables were standardized as preprocessing. The clusters were classified with a threshold Euclidean distance of 10. Figs. S1 - S3 are the dendrograms obtained by the cluster analysis, and Table 2 shows the characteristics of the obtained clusters for each analysis day. The clusters consistently obtained on all analysis days were characterized as follows: pixels with a high proportion of high-buildings (see (a) cluster1, (b) cluster4, and (c) cluster5 in Table 2); pixels with a high proportion of lowbuildings (high density) (see (a) cluster7, (b) cluster7, and (c) cluster2 in Table 2); coastal pixels with a high 
August 12, 2016

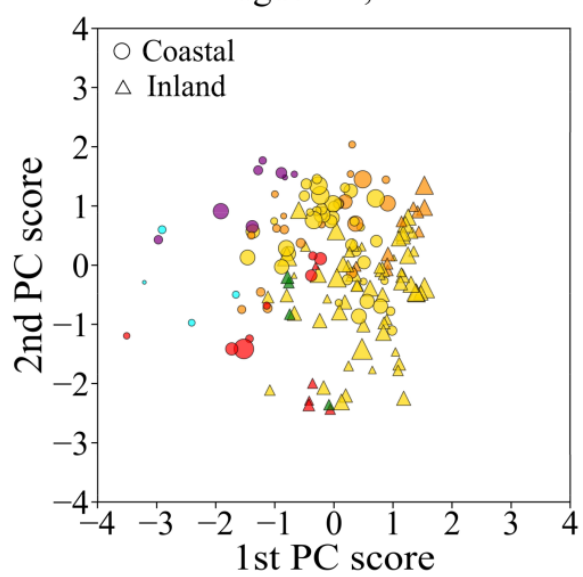

July 19, 2018

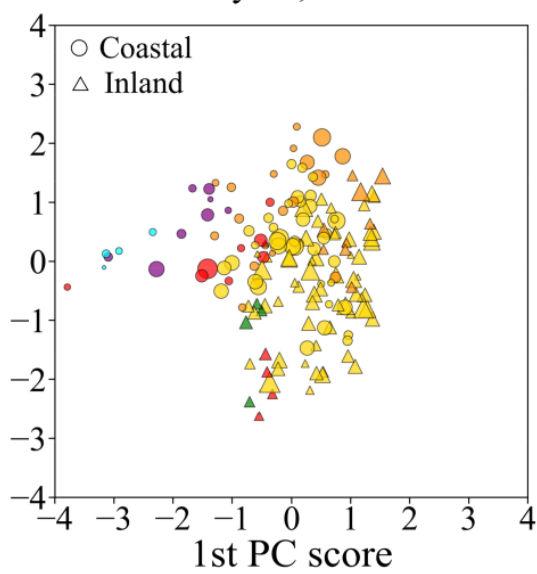

August 4, 2018

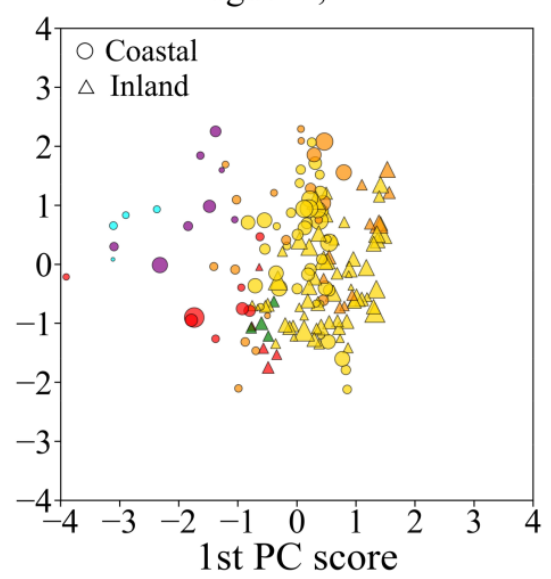

Fig. 4. Scatter diagrams between the PC1 and PC2 scores of the pixels for the three dates in the study area. Of all pixels for each date, half of the pixels close to the coast are indicated by circles as the coastal pixels, and half of the pixels far from the coast are indicated by triangles as the inland pixels. Each pixel is color coded according to land-use type with the highest occupancy, and the marker size corresponds to the occupancy rate.

with a high proportion of low-buildings (low density) (see (a) cluster4, (b) cluster2, and (c) cluster7 in Table 2); coastal pixels with a high proportion of factories (see (a) cluster5, (b) cluster5, and (c) cluster1 in Table 2); inland pixels with a high proportion of vegetation (see (a) cluster3, (b) cluster3, and (c) cluster6 in Table 2); pixels with a high proportion of water body (see (a) cluster6, (b) cluster1, and (c) cluster3 in Table 2). Only on August 12, 2016, pixels with a relatively close Euclidean distance from cluster1 but are located inland were classified as cluster2. This section discusses the consistent or inconsistent characteristics of PC1 and PC2 in three analysis days in terms of the land-sea breeze circulation and urban land use.

\subsection{Relationship between LST and sea breeze}

As shown in Fig. 4, coastal pixels (indicated by circles) tended to have a low PC1 score and a high PC2 score. Conversely, inland pixels (indicated by triangles) tended to have a high PC1 score and a low PC2 score. Such tendencies were aligned with the observation of Yamamoto and Ishikawa (2018a) who considered these to be the results of land and sea breeze circulation, although concrete evidence of the relationship is yet to be found. The variability of the land and sea breeze circulation was accounted herein through a more robust analysis of three different meteorological cases. 
Table 2. Clusters resulting from cluster analysis and their mean characteristics of the input variables on (a) August 12, 2016, (b) July 19, 2018, and (c) August 4, 2018.

(a) August 12, 2016

\begin{tabular}{|c|c|c|c|c|c|c|c|c|c|}
\hline Cluster & 1st PC score & 2nd PC score & $\begin{array}{l}\text { Coastal distance } \\
\text { [pixels] }\end{array}$ & $\begin{array}{c}\text { High-buildings } \\
{[\%]}\end{array}$ & $\begin{array}{c}\text { Low-buildings } \\
\text { (high density) [\%] }\end{array}$ & $\begin{array}{l}\text { Low-buildings } \\
\text { (low density) [\%] }\end{array}$ & Factories [\%] & Vegetation [\%] & Water body [\%] \\
\hline 1 & -1.25 & -0.67 & 4.67 & 43.71 & 13.95 & 7.55 & 0.64 & 2.48 & 5.17 \\
\hline 2 & 0.31 & -1.98 & 8.74 & 27.53 & 2.42 & 42.80 & 1.44 & 10.14 & 2.03 \\
\hline 3 & -0.72 & -0.56 & 8.58 & 3.09 & 0.24 & 46.07 & 3.09 & 33.68 & 4.78 \\
\hline 4 & 0.71 & -0.23 & 8.62 & 8.61 & 4.80 & 63.33 & 2.75 & 4.80 & 4.34 \\
\hline 5 & -1.17 & 1.36 & 2.29 & 2.25 & 2.87 & 10.18 & 40.19 & 1.47 & 16.31 \\
\hline 6 & -0.98 & -0.24 & 5.26 & 11.28 & 10.32 & 20.93 & 9.41 & 1.32 & 27.05 \\
\hline 7 & 0.78 & 0.64 & 6.63 & 11.74 & 47.51 & 22.68 & 0.66 & 1.97 & 1.73 \\
\hline 8 & -0.11 & 0.52 & 4.09 & 9.52 & 15.10 & 42.33 & 6.92 & 3.99 & 6.69 \\
\hline
\end{tabular}

(b) July 19,2018

\begin{tabular}{|c|c|c|c|c|c|c|c|c|c|}
\hline Cluster & 1st PC score & 2nd PC score & $\begin{array}{c}\text { Coastal distance } \\
\text { [pixels] }\end{array}$ & $\begin{array}{c}\text { High-buildings } \\
{[\%]}\end{array}$ & $\begin{array}{c}\text { Low-buildings } \\
\text { (high density) [\%] }\end{array}$ & $\begin{array}{c}\text { Low-buildings } \\
\text { (low density) [\%] }\end{array}$ & Factories [\%] & Vegetation [\%] & Water body [\%] \\
\hline 1 & 0.11 & -0.36 & 7.72 & 15.93 & 10.40 & 30.72 & 3.01 & 0.93 & 26.18 \\
\hline 2 & 0.44 & -0.40 & 7.50 & 11.49 & 5.36 & 57.66 & 2.46 & 5.89 & 4.38 \\
\hline 3 & -0.60 & -0.94 & 8.74 & 3.01 & 0.26 & 43.82 & 3.34 & 35.31 & 4.88 \\
\hline 4 & -0.71 & -1.03 & 6.65 & 50.54 & 3.46 & 13.53 & 0.02 & 10.11 & 3.33 \\
\hline 5 & -2.27 & 0.45 & 2.08 & 5.75 & 2.52 & 11.25 & 29.50 & 1.96 & 19.42 \\
\hline 6 & -0.10 & 0.73 & 3.34 & 6.84 & 23.63 & 34.22 & 9.78 & 1.92 & 7.64 \\
\hline 7 & 0.65 & 0.87 & 6.65 & 14.48 & 46.78 & 19.46 & 0.63 & 1.86 & 1.92 \\
\hline
\end{tabular}

(c) August 4, 2018

\begin{tabular}{|c|c|c|c|c|c|c|c|c|c|}
\hline Cluster & 1st PC score & 2nd PC score & $\begin{array}{l}\text { Coastal distance } \\
\text { [pixels] }\end{array}$ & $\begin{array}{c}\text { High-buildings } \\
{[\%]}\end{array}$ & $\begin{array}{c}\text { Low-buildings } \\
\text { (high density) [\%] }\end{array}$ & $\begin{array}{l}\text { Low-buildings } \\
\text { (low density) [\%] }\end{array}$ & Factories [\%] & Vegetation [\%] & Water body [\%] \\
\hline 1 & -2.27 & 0.82 & 2.08 & 5.75 & 2.52 & 11.25 & 29.50 & 1.96 & 19.42 \\
\hline 2 & 0.65 & 0.60 & 6.58 & 13.63 & 48.23 & 19.51 & 0.58 & 1.90 & 1.77 \\
\hline 3 & -0.20 & -0.93 & 5.49 & 11.17 & 18.56 & 27.99 & 7.17 & 1.10 & 19.42 \\
\hline 4 & 0.05 & 0.85 & 4.28 & 8.89 & 13.47 & 47.55 & 5.68 & 4.61 & 5.65 \\
\hline 5 & -0.93 & -1.14 & 6.65 & 50.54 & 3.46 & 13.53 & 0.02 & 10.11 & 3.33 \\
\hline 6 & -0.54 & -0.73 & 8.91 & 2.96 & 0.05 & 37.10 & 4.68 & 40.43 & 6.00 \\
\hline 7 & 0.56 & -0.49 & 8.33 & 11.47 & 5.14 & 57.79 & 2.60 & 6.45 & 3.52 \\
\hline
\end{tabular}

Fig. 5 shows the penetration time and duration of the sea breeze at each ground observation point for the 3 days.

184 Penetration time and end time of the sea breeze were judged on the basis of changes in wind direction/speed and 185 SAT. Thus, the westerly wind $\left(270^{\circ} \pm 22.5^{\circ}\right)$ at Sakai and Yao, and southwesterly wind $\left(225^{\circ} \pm 22.5^{\circ}\right)$ at Osaka and 186 Toyonaka were regarded as the sea breeze, respectively. The penetration time was defined as the time when the wind speed increased, its direction continued for more than $30 \mathrm{~min}$, and the SAT decreased within $30 \mathrm{~min}$. The end time was judged as the time when the wind speed decreased and the wind direction began to change in a direction other than that of the sea breeze. More detailed wind direction/speed and SAT time-series changes are shown in Figs. S4-S6.

Sea breeze causes reduction in both the SAT and the LST. Thus, the trend of the low PC1 score of coastal pixels was thought to be due to the suppression of LST rise by a cool sea breeze, which reduced PC1's amplitude. Moreover, the differences between the coastal and inland PC2 scores were thought as a result of the penetration time and duration of the sea breeze. The sea breeze characteristics for the August 12, 2016, case showed the least amount of regional 


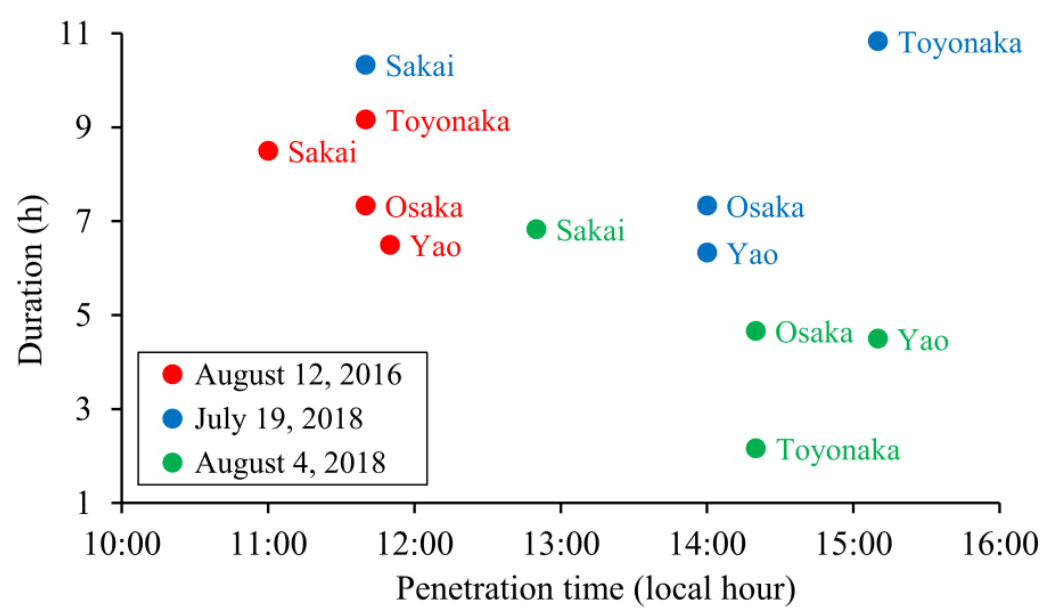

Fig. 5. Penetration time and duration of the sea breeze observed at the stations of AMeDAS in the study area on the three analysis dates.

195 variability compared with the other two cases (see Fig. 5). As shown in Fig. 2a, the components of PC2 eigenvector on August 12, 2016, did not have a clearly defined minimum value in the afternoon. In other words, the leaning of the wave on this day was affected by the heating rate in the morning rather than the cooling rate in the afternoon.

This result can be explained by the fact that not much regional difference occurred in the penetration time and duration of the sea breeze. Thus, the cooling effect of the sea breeze without regional difference may have reduced the regional difference of LST cooling rate during the afternoon.

For the other 2 days, regional differences in the penetration time were large (Fig. 5), especially on July 19, 2018, whose duration was longer than on August 4, 2018. The components of PC2 eigenvectors in the afternoon on these 2 days took smaller minimum values than those on August 12,2016, which can be attributed from the regional difference in penetration time and duration of the sea breeze contrary to the case on August 12, 2016. In addition, the duration on July 19, 2018, was long, potentially causing large regional difference in the degree of the LST drop. As a result, $\mathrm{PC} 2$ contribution ratio may have become large (Table 1), and the PC2 score of the coastal pixels likewise became large, as compared with those of the other 2 days (Fig. 4).

\subsection{Relationship between LST and urban land use}

As shown in Fig. 4 and Table 2, the pixels occupied by high-buildings, factories, vegetation, or bodies of water tended to exhibit a low PC1 score, whereas that of pixels occupied by low-buildings (high/low density) tended to be high. Such tendency could be attributed to the thermal inertia of the surface material. Thermal inertia is a thermal 
213 Kondo, 1995; Haffner and Kidder, 1999; Zhan et al., 2012). As water surface has large thermal inertia, the amplitude

214 of the diurnal cycle at pixels occupied by the water bodies is small. In urban land-use areas, the amplitudes of the diurnal cycle may reflect the thermal inertia of building roof and wall materials rather than the road materials since the satellite zenith angle of Himawari-8 in the analysis area is about $40^{\circ}$. High-buildings and factories mainly consist of concrete, glass and metal, which similarly show large thermal inertia. By contrast, low-buildings mainly consist of wooden materials and slate roof that have small thermal inertia. Thus, differences in the building materials were thought to have caused variation in the PC1 amplitude. A similar interpretation was made by previous studies using polar-orbiting satellite/aircraft sensors, from the viewpoint of the thermal inertia or heat capacity of building materials (e.g., Li et al., 2011; Tsunematsu et al., 2016). However, depending on the width among building clusters and street orientation, more road surfaces are observed, and it is necessary to consider surface materials such as asphalt with high thermal inertia. As shown in Table 2 (a) cluster5, (b) cluster5, and (c) cluster1, the pixels occupied by the factories and water bodies may have been affected by the cooling effect of the sea breeze, being proximal to the coast. Regarding the vegetated areas, transpiration was believed to have suppressed LST rise at daytime.

With regard to PC2, pixels occupied by the low-buildings (high density) tended to have high scores regardless of the area as coastal and inland. The values of thermal inertia were thought to have varied from large to small, as the land use changed from high-buildings, low-buildings (high density), and to low-buildings (low density) with the decrease in concrete buildings and the increase in wooden buildings (Haffner and Kidder, 1999; Tsunematsu et al., 2016). The larger the thermal inertia, the smaller was the amplitude (i.e., lower PC1 score) and the later the phase (i.e., higher PC2 score). Nonetheless, only those pixels occupied by the low-buildings (high density) were biased to the first quadrant in Fig. 4 (i.e., high PC1 and PC2 scores, shown in Table 2 (a) cluster7, (b) cluster7, and (c) cluster2).

This possibly be because more road surfaces with high thermal inertia have been observed in low-buildings (low density). In addition, differences in surface roughness between high/low building densities may have different heat balance processes in the diurnal cycle on the clear-sky days.

The shadows of buildings during the daytime suppress the temperature rise of the land surface and cause a decrease in the amplitude of the diurnal cycle. Depending on the street orientations, the timing affected by the shadows may vary, which may change the PC2 score. The shadow effects are considered to have been most significant in the highbuildings, which have high building height and large variations of the building height. The shadow effects also vary 
between buildings. In order to clarify the relationship between building arrangement and the amplitude/phase in the diurnal cycle, the LST and land-use data with higher spatial resolutions (less than $100 \mathrm{~m}$ ) are needed.

Fig. 6 shows the diurnal LST changes calculated using average PC1 and PC2 scores and daily mean LST of the coastal pixels occupied by high-buildings, low-buildings (high density), and low-buildings (low density). LST at nighttime was lower in the order of high-buildings, low-buildings (high density), and low-buildings (low density), which could be due to the thermal inertia of the building materials as described above. However, the order during daytime was not reversed of that during nighttime, and the low-buildings (high density) had the highest LST, implying an increase in internal reflections of solar and infrared radiations, along with wind speed reduction between the buildings as their density increased. More complex internal reflection of the radiations implies higher absorptivity and thereby causes higher heating rate at daytime. Moreover, at a location where variation in building height was small and that for building density was high, the wind above the group of buildings hardly blew into spaces between the buildings (Hagishima et al., 2004). The convective heat transfer between the surface within street canyons (mainly building walls and roads) and the atmosphere near it decreases under weak wind conditions. The LST retrieved from Himawari-8 in the analysis area reflects the surface temperatures of more building roofs and walls in the street canyons as the building density increases. Thus, these effects in radiation and wind fields may have resulted in a larger rate of LST increase in the morning, and the waveform of the diurnal change leaned forward (i.e., the PC2 score increased) in the pixels occupied by low-buildings (high density).

LST differences between low-buildings (high density) and low-buildings (low density) shown in Fig. 6 may also be due to differences in vegetation cover since vegetation reduces daytime and nighttime LST by transpiration.

August 12, 2016

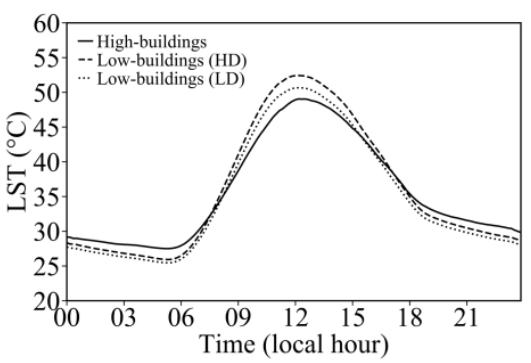

July 19, 2018

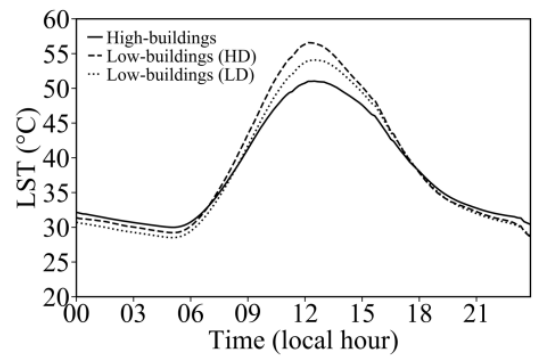

August 4, 2018

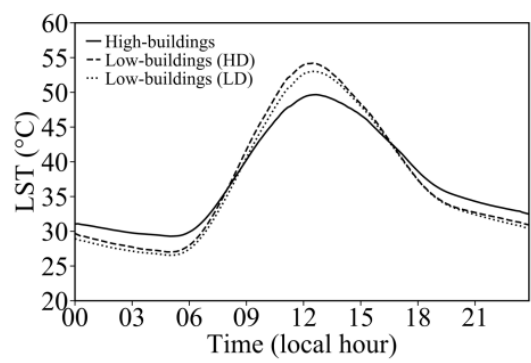

Fig. 6. Diurnal LST changes calculated with average PC1 and PC2 scores and daily mean LST of the coastal pixels where occupancy rate of high-buildings, low-buildings (high density), and low-buildings (low density) are higher than $70 \%$. The solid, dashed, and dotted lines show the diurnal LST changes of high-buildings, lowbuildings (high density), and low-buildings (low density), respectively. 
261 However, the mean proportions of vegetation class of pixels used in Fig. 6 were 1.07\% for low-buildings (high density) and 3.28\% for low-buildings (low density). The mean normalized difference vegetation index (NDVI) values on three analysis days were $0.30,0.29$, and 0.35 for low-buildings (high density), $0.32,0.29$, and 0.34 for lowbuildings (low density). These small differences in vegetation cover are unlikely to have a significant effect on the diurnal LST changes shown in Fig. 6.

The difference in the surface material may also be a cause of LST differences between low-buildings (high density) and low-buildings (low density) shown in Fig. 6. In Japan, as distance to the city center decreases the proportion of concrete buildings increases whilst that of wood buildings decreases (Tsunematsu et al., 2016). The trend suggests that the effective thermal inertia is greater in the low-buildings (high density), but this is inconsistent with the larger amplitude of the low-buildings (high density) shown in Fig. 6. Besides, if the building materials in low-buildings (high density) were the same as those in low-buildings (low density), surface in low-buildings (high density) is covered by more roofs and walls (e.g., slate and wooden materials) and fewer roads (e.g., asphalt and concrete) compared with that in low-buildings (low density). In this case, the effective thermal inertia of the low-buildings (high density) is smaller than that of the low-buildings (low density), so the temperature should drop significantly during nighttime. This is also inconsistent with the nighttime LST shown in Fig. 6. Since the spatial resolution of Himawari-8 is low, it is challenging to discuss the relationship between a temporal LST change and surface materials in detail. However, it is difficult to interpret the results showing that the high-density areas of low-buildings were the hottest during the daytime, based solely on the thermal inertia of the surface materials.

\section{Conclusions}

This study exploited the high spatiotemporal resolution of Himawari-8 sensor for investigation of the influence of sea breeze and urban spatial configuration on the temporal changes of LST. The study area was an urban area of Osaka Plain, Japan, for target clear-sky days in midsummer. Temporal changes of the LST were defined as the principal temporal change characteristics forming the diurnal changes of LST, extracted via the PCA. The extracted characteristics included the amplitude and phase (waveform leaning) of the diurnal cycle, whose spatial variabilities were investigated using ground-based meteorological observation and land-use data of the study area. 
289 importance of considering the effect of land and sea breeze circulation when observing LST in coastal cities. The 290 eigenvalues (contribution ratio) and scores of PC2 have a potential application in assessing the effects of sea breeze 291 on LST and urban heat island patterns. Note that on cloudy days or in the winter season, the diurnal changes of LST 292 are small, and the characteristics of the land-sea breeze circulation are different from those on summer clear-sky 293 days. On such days, different temporal change characteristics from those in this analysis are expected.

294 As for the relationship with land-use data, the variations of PC1 and PC2 scores were confirmed to correspond to 295 the thermal inertia of the building materials, which is consistent with previous studies. Furthermore, pixels occupied 296 by the low-buildings (high density) yielded high scores for both PC1 and PC2, regardless of the area as coastal and 297 inland. At daytime, low-buildings (high density) tended to exhibit higher LST than high-buildings and low-buildings 298 (low density), which suggests the impact of building density on diurnal LST change. The findings of this study 299 provide new facts on the relationship between LST and urban spatial configuration, as has been suggested in previous 300 studies (Li et al., 2011; Connors et al., 2013). Furthermore, such findings contribute to a deeper understanding of the 301 hot environment. The combined knowledge of a spatial LST pattern derived from an aircraft or polar-orbiting satellite 302 and the diurnal LST patterns, including the effects of building density and sea breeze, derived from a new-generation 303 geostationary satellite, would help urban planners mitigate its deterioration due to urbanization. For example, 304 applying the presented analysis method to the rapidly urbanizing Asia-Megacities would contribute to improve the 305 thermal environment measures of each city.

\section{Acknowledgments}

We would like to thank Dr. Alex Poulidis from Kyoto University for his insightful discussions and comments on the manuscript.

Declarations of interest: none.

Budd, G.M., 2008. Wet-bulb globe temperature (WBGT)-its history and its limitations. J. Sci. Med. Sport 11, 20-32. https://doi.org/10.1016/j.jsams.2007.07.003 
relationship between landscape characteristics and land surface temperature in Phoenix, Arizona. Landsc. Ecol. 28, 271-283. https://doi.org/10.1007/s10980-012-9833-1

Hafner, J., and Kidder, S. Q., 1999. Urban heat island modeling in conjunction with satellite-derived surface/soil parameters. Journal of Applied Meteorology, 38, 448-465.

Hagishima, A., Tanimoto, J., Narita, K., 2004. Review of the former researches on the convective heat transfer coefficient of urban surfaces. J. Japan Soc. Hydrol. Water Resour. 17, 536-554.

Honjo, T., Tsunematsu, N., Yokoyama, H., 2017. Urban climate analysis of urban surface temperature change using structure- from-motion thermal mosaicing. Urban Clim. 20, 135-147. https://doi.org/10.1016/j.uclim.2017.04.004

Japan Fire and Disaster Management Agency, 2018. The emergency conveyance situation due to heat stroke of 2018 (May to September), (17 pp.) (in Japanese).

Japan Statistics Bureau, 2019. Statistical observations of prefectures 2019, (164 pp.) (in Japanese).

Jendritzky, G., De Dear, R., Havenith, G., 2012. UTCI—Why another thermal index? Int. J. Biometeorol. 56, 421-428. https://doi.org/10.1007/s00484-011-0513-7

Kim, Y.-H., Baik, J.-J., 2005. Spatial and temporal structure of the urban heat island in Seoul. J. Appl. Meteorol. 44, 591-605. https://doi.org/10.1175/JAM2226.1

Kusaka, H., Hara, M., Takane, Y., 2012. Urban climate projection by the WRF model at 3-km horizontal grid increment:

Li, J., Wang, X., Wang, X., Ma, W., Zhang, H., 2009. Remote sensing evaluation of urban heat island and its spatial

Memon, R.A., Leung, D.Y.C., Liu, C.H., 2009. An investigation of urban heat island intensity (UHII) as an indicator of urban heating. Atmos. Res. 94, 491-500. https://doi.org/10.1016/j.atmosres.2009.07.006

Oku, Y., Masumoto, K., 2014. An observational study of the difference on urban heat islands between summer and winter in Osaka city. J. Heat Isl. Inst. Int. 9, 1-12 (in Japanese with English abstract).

Saitoh, T.S., Shimada, T., Hoshi, H., 1996. Modeling and simulation of the Tokyo urban heat island. Atmos. Environ. 30, 
$3431-3442$.

346 Seino, N., Aoyagi, T., Tsuguti, H., 2018. Numerical simulation of urban impact on precipitation in Tokyo: How does urban temperature rise affect precipitation? Urban Clim. 23, 8-35. https://doi.org/10.1016/j.uclim.2016.11.007

Sugawara, H., Kondo, J., 1995. Sensitivity test of urban surface temperature. Tenki 42, 813-818 (in Japanese).

Suzuki, T., Iizuka, Y., 2009. Diurnal temperature changing patterns of Tokyo according to season and weather. Tenki 56, 627-635 (in Japanese).

Tsunematsu, N., Yokoyama, H., Honjo, T., Ichihashi, A., Ando, H., Shigyo, N., 2016. Relationship between land use variations and spatiotemporal changes in amounts of thermal infrared energy emitted from urban surfaces in

Tzavali, A., Paravantis, J.P., Mihalakakou, G., Fotiadi, A., Stigka, E., 2015. Urban heat island intensity: A literature review. Fresenius Environ. Bull. 24, 4537-4554.

Weng, Q., 2009. Thermal infrared remote sensing for urban climate and environmental studies: Methods, applications, and trends. ISPRS J. Photogramm. Remote Sens. 64, 335-344. https://doi.org/10.1016/j.isprsjprs.2009.03.007

Xu, L.Y., Xie, X.D., Li, S., 2013. Correlation analysis of the urban heat island effect and the spatial and temporal distribution of atmospheric particulates using TM images in Beijing. Environ. Pollut. 178, 102-114. https://doi.org/10.1016/j.envpol.2013.03.006

Yamamoto, Y., Ishikawa, H., 2018a. Spatiotemporal variability characteristics of clear-sky land surface temperature in urban areas of Japan observed by Himawari-8. Sola 14, 179-184. https://doi.org/10.2151/sola.2018-032

Yamamoto, Y., Ishikawa, H., 2018b. Thermal land surface emissivity for retrieving land surface temperature from Himawari-8. J. Meteorol. Soc. Japan 96B, 43-58. https://doi.org/10.2151/jmsj.2018-004

Yamamoto, Y., Ishikawa, H., Oku, Y., Hu, Z., 2018. An algorithm for land surface temperature retrieval using three estimation of urban thermal inertia. Remote Sens. Environ. 123, 12-24. 


\title{
Supplementary materials
}

\section{Influence of urban spatial configuration and sea breeze on}

\author{
land surface temperature on summer clear-sky days \\ Yuhei Yamamoto ${ }^{1}$ and Hirohiko Ishikawa ${ }^{1}$ \\ 'Disaster Prevention Research Institute, Kyoto University, Kyoto, Japan.
}

Corresponding author: Yuhei Yamamoto

*Present address: Center for Environmental Remote Sensing, Chiba University, 1-33 Yayoi-cho, Inage-ku, Chiba-shi, Japan.

E-mail: yamamoto_y@storm.dpri.kyoto-u.ac.jp

\section{Contents of this file}

Fig. S1

Fig. S2

Fig. S3

Fig. S4

Fig. S5

Fig. S6 


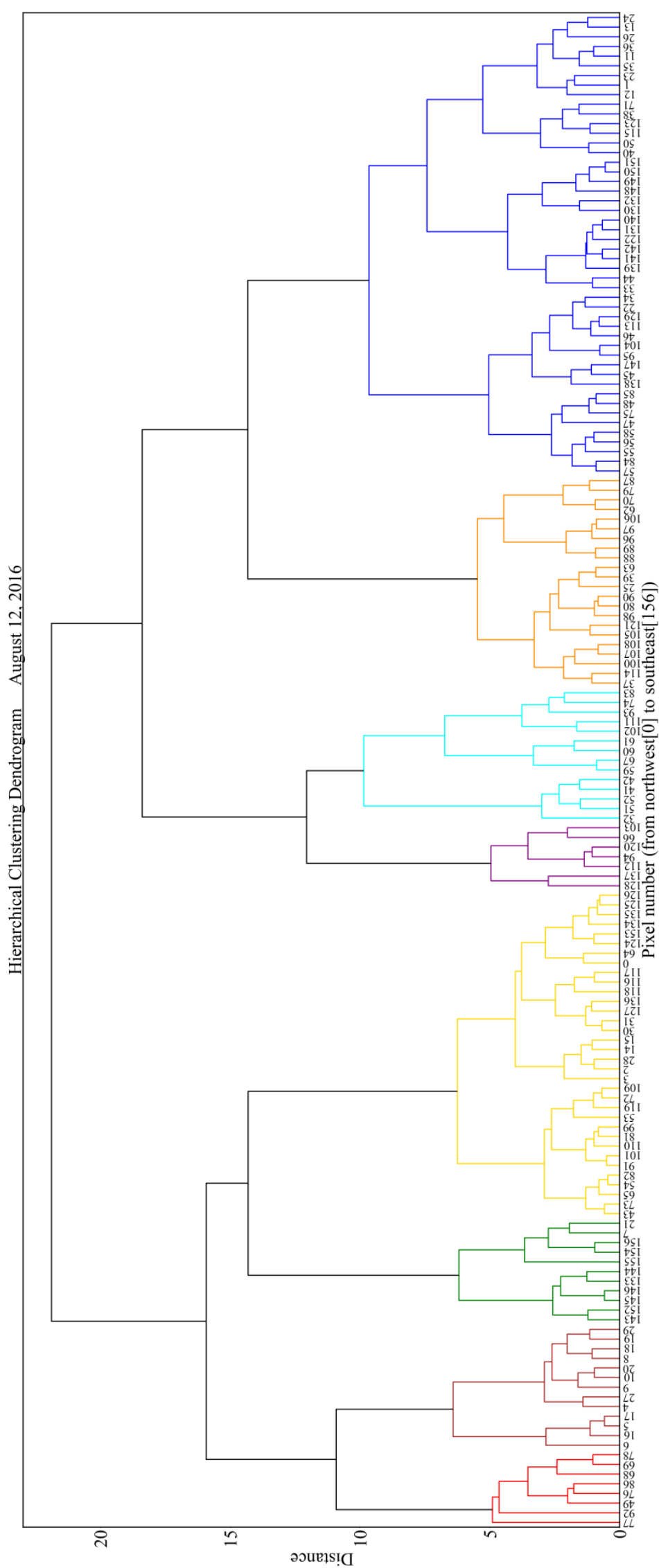

Fig. S1. Dendrograms obtained by the cluster analysis (Ward's method) on August 12, 2016. The horizontal axis represents the pixel number, and the vertical axis represents the Euclidean distance. 


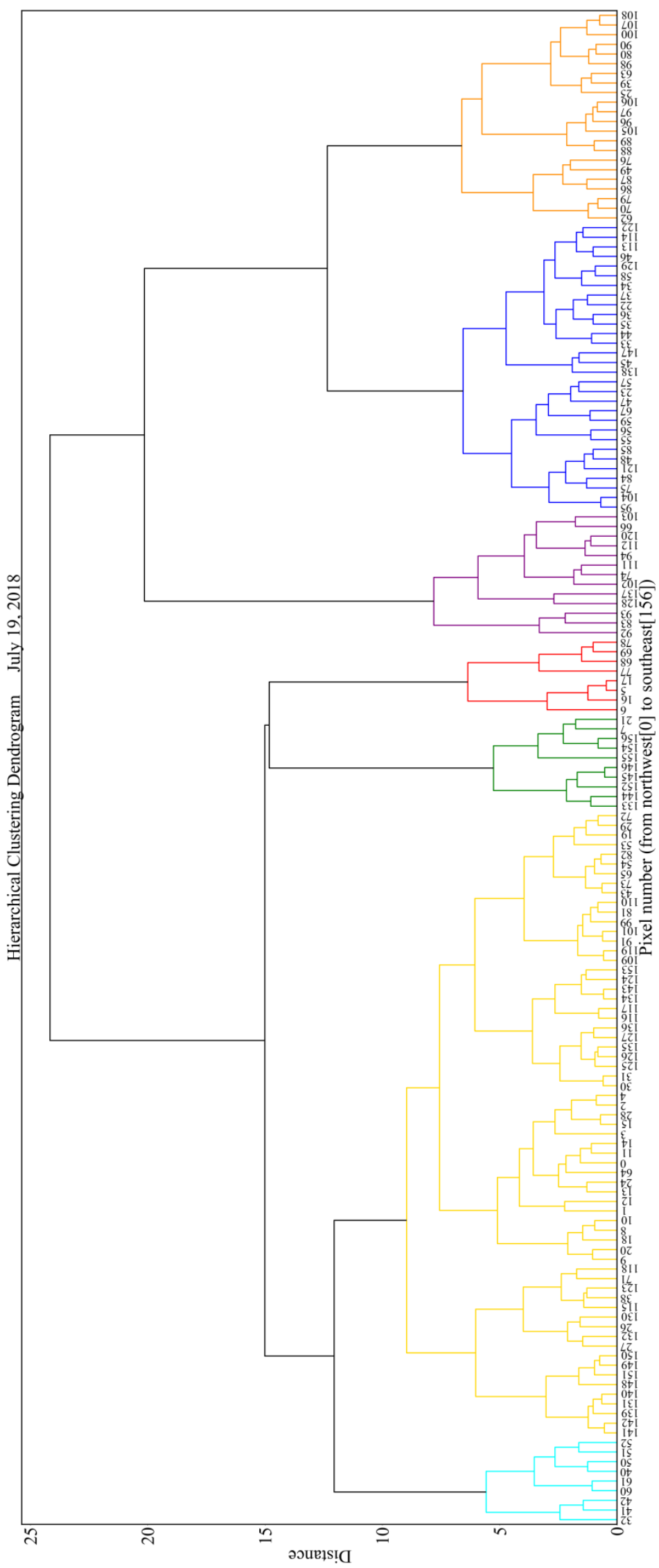

Fig. S2. Similar to Fig. S4, but for July 19, 2018. 


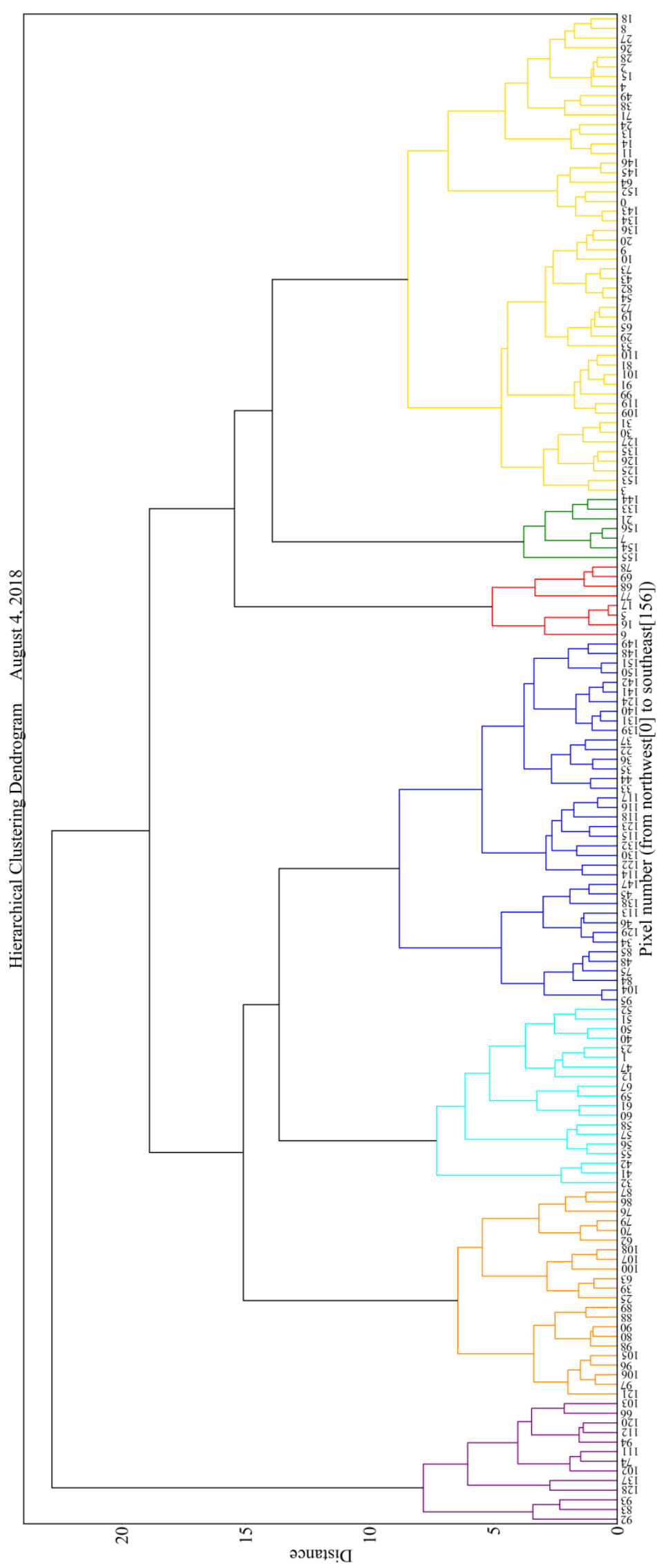

Fig. S3. Similar to Fig. S4, but for August 4, 2018. 

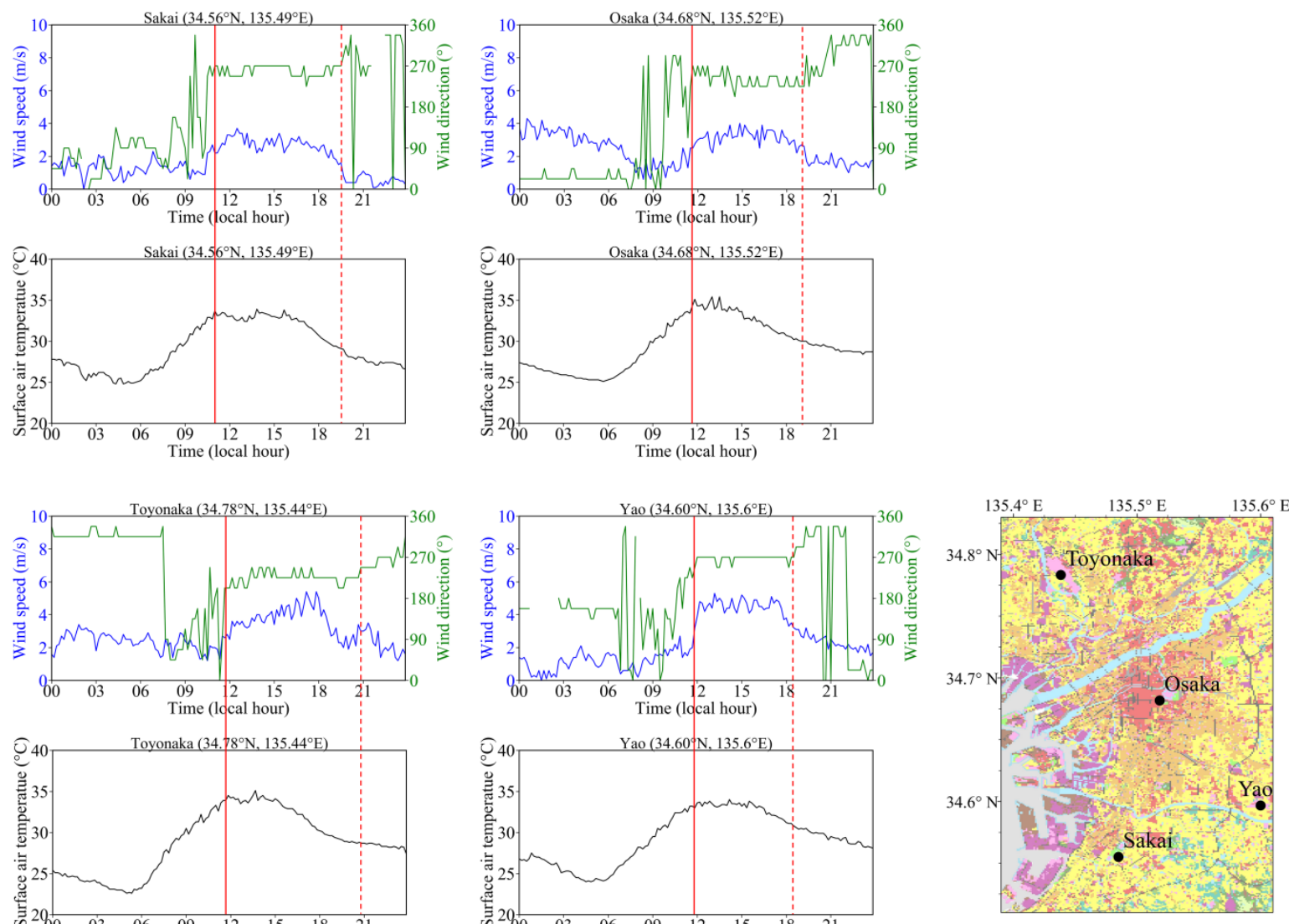

Fig. S4. Time series data of wind speed/direction and SAT observed at the stations of AMeDAS in the study area on August 12, 2016. The lower right figure shows the position of each observation point in the study area. The red solid lines indicate penetration times of the sea breeze roughly judged by changes in wind direction, increase in wind speed, and decrease in SAT. The end times of the sea breeze judged by the change in wind direction and wind speed are indicated by a red dashed line. 

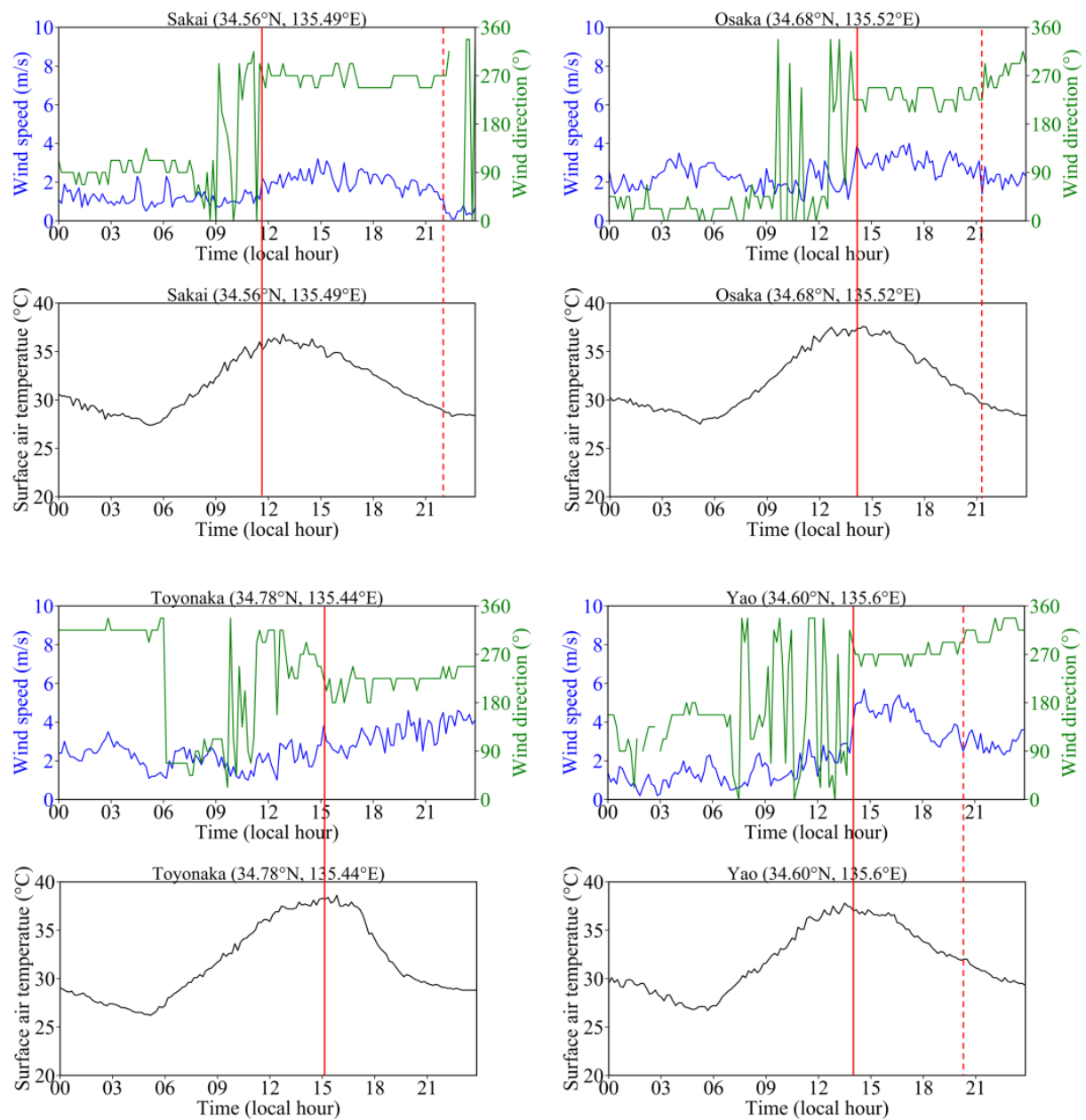

Fig. S5. Similar to Fig. S1, but for July 19, 2018 

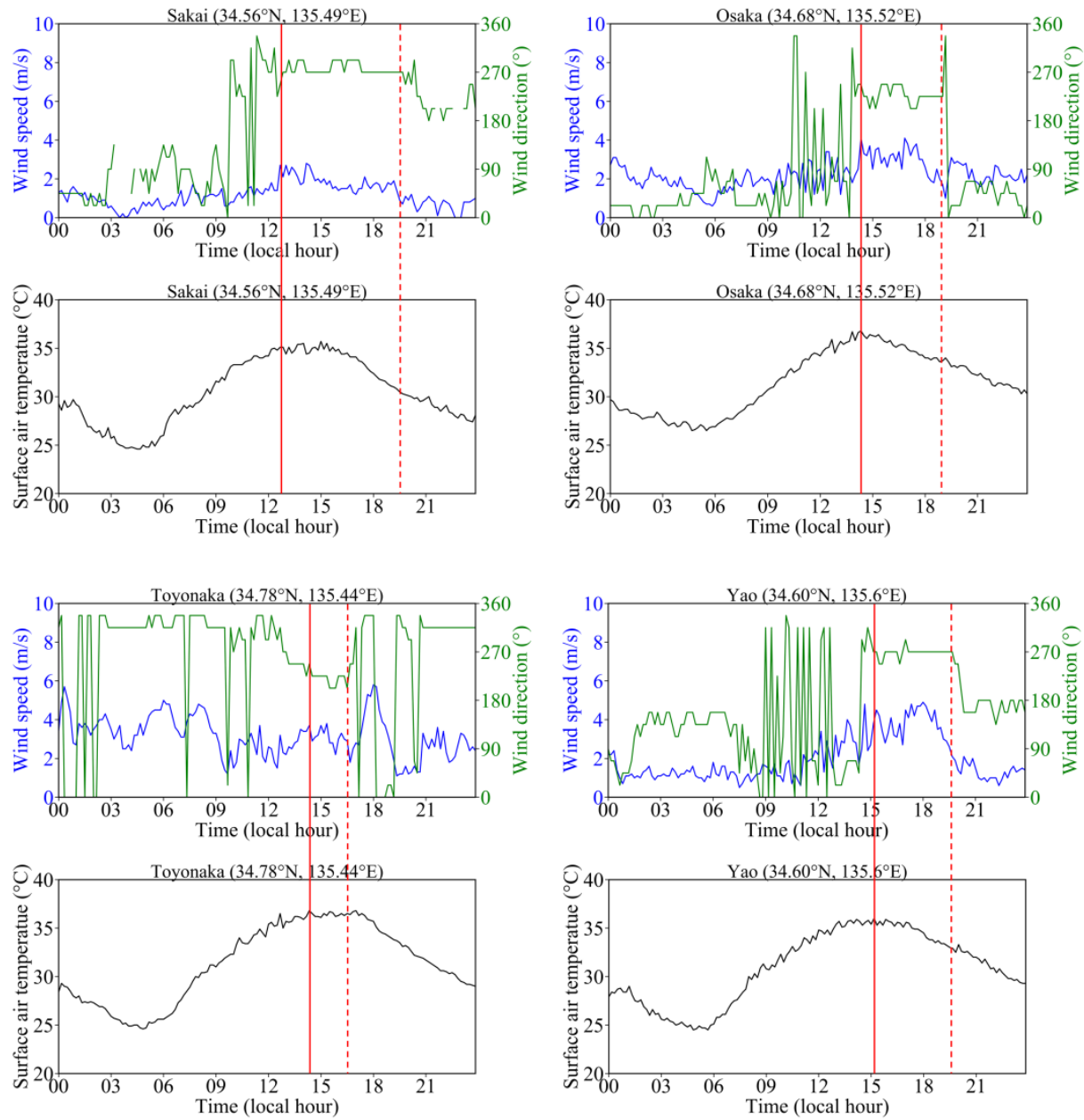

Fig. S6. Similar to Fig. S1, but for August 4, 2018. 


\section{Declaration of interests}

$\bigotimes$ The authors declare that they have no known competing financial interests or personal relationships that could have appeared to influence the work reported in this paper.

$\bigotimes$ The authors declare the following financial interests/personal relationships which may be considered as potential competing interests:

Declarations of interest: none 


\section{CRediT author statement}

Yuhei Yamamoto: Conceptualization, Data curation, Formal analysis, Investigation, Methodology, Project administration, Software, Validation, Visualization, Writing - original draft, Writing - review \& editing.

Hirohiko Ishikawa: Funding acquisition, Resources, Supervision 


\section{Urban Climate}

\section{Conflict of interest declaration and author agreement form}

Title of Paper: Influence of urban spatial configuration and local meteorological field on land surface temperature on summer clear-sky days

1) We wish to confirm that there are no known conflicts of interest associated with this publication and there has been no significant financial support for this work that could have influenced its outcome.

2) We confirm that the manuscript has been read and approved by all named authors and that there are no other persons who satisfied the criteria for authorship but are not listed. We further confirm that the order of authors listed in the manuscript has been approved by all of us.

3) We confirm that neither the entire paper nor any of its content has been submitted, published, or accepted by another journal. The paper will not be submitted elsewhere if accepted for publication in the journal.

4) We confirm that we have given due consideration to the protection of intellectual property associated with this work and that there are no impediments to publication, including the timing of publication, with respect to intellectual property. In so doing we confirm that we have followed the regulations of our institutions concerning intellectual property.

5) We understand that the Corresponding Author is the sole contact for the Editorial process (including Editorial Manager and direct communications with the office). He is responsible for communicating with the other authors about progress, submissions of revisions and final approval of proofs.

Signed by all authors as follows:

\section{Print name}

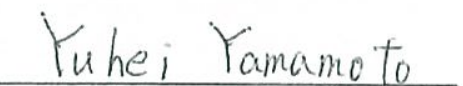

Author signature
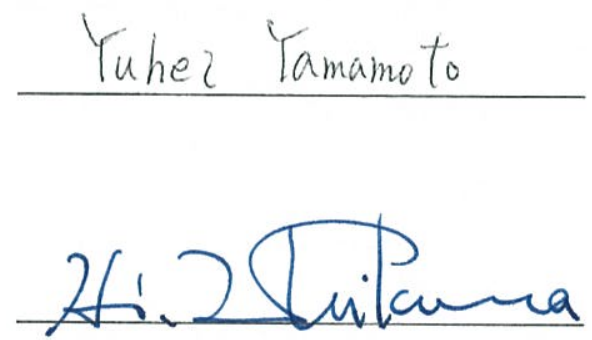

Date

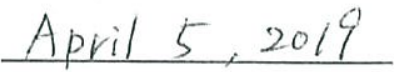

